\title{
BMJ Open Occupational noise-induced hearing loss in China: a systematic review and meta-analysis
}

\author{
Jiena Zhou (D) , ${ }^{1}$ Zhihao Shi, ${ }^{2}$ Lifang Zhou, ${ }^{1}$ Yong Hu, ${ }^{1}$ Meibian $Z$ hang ${ }^{1}$
}

To cite: Zhou J, Shi Z, Zhou L, et al. Occupational noiseinduced hearing loss in China: a systematic review and meta-analysis. BMJ Open 2020;10:e039576. doi:10.1136/ bmjopen-2020-039576

- Prepublication history for this paper is available online To view these files, please visit the journal online (http://dx.doi org/10.1136/bmjopen-2020039576).

Received 21 April 2020 Revised 06 August 2020 Accepted 19 August 2020
Check for updates

(C) Author(s) (or their employer(s)) 2020. Re-use permitted under CC BY-NC. No commercial re-use. See rights and permissions. Published by BMJ.

${ }^{1}$ Occupational Health and Radiation Protection Department, Zhejiang Provincial Center for Disease Control and Prevention, Hangzhou, China

${ }^{2}$ School of medicine, Ningbo University, Ningbo, China

Correspondence to Dr Meibian Zhang; mbzhang@cdc.zj.cn

\section{ABSTRACT}

Objective Most of the Chinese occupational population are becoming at risk of noise-induced hearing loss (NIHL). However, there is a limited number of literature reviews on occupational NIHL in China. This study aimed to analyse the prevalence and characteristics of occupational NIHL in the Chinese population using data from relevant studies.

Design Systematic review and meta-analysis.

Methods From December 2019 to February 2020, we searched the literature through databases, including Web of Science, PubMed, MEDLINE, Scopus, the China National Knowledge Internet, Chinese Sci-Tech Journal Database (weip. com), WanFang Database and China United Library Database, for studies on NIHL in China published in 1993-2019 and analysed the correlation between NIHL and occupational exposure to noise, including exposure to complex noise and coexposure to noise and chemicals.

Results A total of 71865 workers aged $33.5 \pm 8.7$ years were occupationally exposed to $98.6 \pm 7.2 \mathrm{~dB}(\mathrm{~A})$ (A-weighted decibels) noise for a duration of $9.9 \pm 8.4$ years in the transportation, mining and typical manufacturing industries. The prevalence of occupational NIHL in China was $21.3 \%$, of which $30.2 \%$ was related to high-frequency NIHL (HFNIHL), 9.0\% to speech-frequency NIHL and 5.8\% to noise-induced deafness. Among manufacturing workers, complex noise contributed to greater HFNIHL than Gaussian noise (overall weighted $\mathrm{OR}(\mathrm{OR})=1.95)$. Coexposure to noise and chemicals such as organic solvents, welding fumes, carbon monoxide and hydrogen sulfide led to greater HFNIHL than noise exposure alone (overall weighted $\mathrm{OR}=2.36$ ). Male workers were more likely to experience HFNIHL than female workers (overall weighted $\mathrm{OR}=2.26$ ). Age, noise level and exposure duration were also risk factors for HFNIHL (overall weighted $\mathrm{OR}=1.35$, 5.63 and 1.75 , respectively).

Conclusions The high prevalence of occupational NIHL in China was related to the wide distribution of noise in different industries as well as high-level and long-term noise exposure. The prevalence was further aggravated by exposure to complex noise or coexposure to noise and specific chemicals. Additional efforts are needed to reduce occupational noise exposure in China.

\section{INTRODUCTION}

Hearing loss is the most prevalent sensory disability worldwide, and noise-induced hearing loss (NIHL) has been a global public health problem. NIHL is a type of progressive sensorineural hearing loss caused by noise exposure.

\section{Strengths and limitations of this study}

The study attempts to addresses the limited number of literature reviews on occupational noise-induced hearing loss in China.

- A very large sample of workers with harmful exposure to occupational noise were included in the study.

- Our findings could provide a basis for the early prevention and control of occupational noise-induced hearing loss and the implementation of hearing protection programmes in China and other low/middleincome countries.

- The number of Chinese studies focusing on speechfrequency noise-induced hearing loss and deafness was limited, resulting in an insufficient sample in these categories.

- There were no well-designed prospective studies on noise, and there were insufficient cohort studies on the topic.

With the rapid development of industrialisation, people are increasingly becoming at risk of NIHL. WHO estimated that $10 \%$ of the global population are exposed to noise pollution, of whom $5.3 \%$ experience NIHL. ${ }^{12}$

Approximately $16 \%$ of adult hearing loss cases are associated with exposure to noise in the workplace. ${ }^{3}$ Occupational NIHL is the most prevalent occupational disease worldwide, with $>10 \%$ of workers in developed countries having NIHL. ${ }^{4}$ About 600 million workers are exposed to harmful levels of noise globally. ${ }^{5}$ Each year, about 22 million workers are exposed to harmful levels of noise in the USA, ${ }^{6}$ while about 1.7 million workers are exposed to $>85 \mathrm{~dB}(\mathrm{~A})$ (A-weighted decibels) of noise in Britain. ${ }^{7}$ Occupational noise-induced deafness (NID) accounts for $>60 \%$ of all occupational diseases reported in Norway. ${ }^{8}$ From 2002 to $2005,16.2 \% \%-22.9 \%$ of Korean workers were exposed to workplace noise exceeding $85 \mathrm{~dB}(\mathrm{~A})$, and 4483 workers had NID. ${ }^{9}$ In China, $>10$ million workers are exposed to harmful noise. ${ }^{10}$ In recent years, China has been facing a change in the spectrum of occupational diseases, that is, NID followed by 
pneumoconiosis has replaced occupational poisoning as the second most common occupational disease, with an annual increase of $20 \% .{ }^{11}$ The prevalence of occupational NIHL in China is estimated to be $>20 \% .{ }^{12}$ In some low/middle-income countries, workers exposed to noise in the transportation and manufacturing industries account for a high prevalence of NIHL, ranging from $18 \%$ to $67 \% .{ }^{1314}$

Industrial noise may consist of steady noise (Gaussian noise) or complex noise (non-Gaussian noise), with the latter being the dominant type in the workplace. Complex noise is composed of transient high-energy impulsive noise superimposed on stationary (Gaussian) background noise. ${ }^{15}$ Animal experiments and a few epidemiological surveys revealed that exposure to complex noise could lead to greater hearing damage and is not only associated with noise energy but also with its complex temporal structure. ${ }^{16}$ These findings have challenged the appropriateness of the international noise exposure standard (ISO-1999, 2013) ${ }^{1718}$ and the safety of the occupational exposure limit of noise (eg, $85 \mathrm{~dB}(\mathrm{~A})$ ), in which the measurement of noise energy (the equivalent sound level) serves as the sole method for evaluating noise based on the "equal energy hypothesis. ${ }^{19-21}$ Currently, kurtosis is considered a good parameter for reflecting the temporal structure and impulsiveness of noise, and its combination with energy is an effective indicator for evaluating hearing loss caused by complex noise. ${ }^{22}{ }^{23}$ In addition, combined exposure to noise and chemicals may exacerbate hearing loss. ${ }^{104-27}$ Epidemiological studies have shown that exposure to mixed organic solvents is associated with an excessive risk of developing hearing loss, with or without concurrent noise exposure, in humans. Workers from a wide range of industrial sectors, whose jobs involve the use of paints, thinners, lacquers and printing inks, are usually exposed to mixtures of xylene, toluene, benzene, methyl ethyl ketone.

Although a large number of workers in China are reported to be at high risk of developing NIHL, the epidemiological characteristics and prevalence of NIHL are not well understood, and there is a limited number of literature reviews on the topic. This study, therefore, aimed to review the literature regarding NIHL in the Chinese occupational population and analyse the data to understand the prevalence and characteristics of NIHL in the workplace, including exposure to different types of noise or coexposure to noise and chemicals. Our findings could provide a basis for the early prevention and control of occupational NIHL and the implementation of hearing protection programmes in China and other low/ middle-income countries.

\section{METHODS}

\section{Literature retrieval}

We used English literature databases such as the Web of Science, PubMed, MEDLINE and Scopus. We also searched Chinese literature databases including the China National Knowledge Internet, Chinese Sci-Tech Journal Database ( weip.com), WanFang Database and China United Library Database. The keywords searched were "noise-induced hearing loss," "noise and hearing loss," "noise-induced deafness," "NIHL," "hearing threshold shift," "complex noise," "co-exposure," and "noise and chemical exposure." The date of search was between December 2019 and February 2020.

\section{Inclusion and exclusion criteria}

We included studies on overt hearing loss associated with occupational exposure to noise in Chinese populations published in Chinese and English journals from 1993 to 2019. The inclusion criteria were as follows: (1) studies with Chinese subjects, (2) studies whose subjects had a clear history of occupational exposure to noise and (3) studies in accordance with an occupational health standard in China (eg, Diagnosis of Occupational NID, GBZ 49-2014).$^{28}$ High-frequency NIHL (HFNIHL) was defined as an average hearing threshold of $\geq 40 \mathrm{~dB}$ for binaural high-frequency sound $(3,4$ and $6 \mathrm{kHz})$ or an average hearing threshold in either ear of $\geq 30 \mathrm{~dB}$ at 3,4 and 6 $\mathrm{kHz}$. Speech-frequency NIHL (SFNIHL) was defined as an average hearing threshold of $\geq 26 \mathrm{~dB}$ in the better ear at speech frequencies of 500, 1000 and $2000 \mathrm{~Hz}$. Meanwhile, NID was defined according to the average hearing threshold for high-frequency and speech-frequency sounds, progressive hearing loss, tinnitus and other symptoms, and pure-tone audiometry results for sensorineural deafness.

The exclusion criteria were as follows: (1) studies on hearing loss or deafness that was not associated with occupational exposure to noise; (2) studies on noise exposure not associated with the auditory system; (3) studies on the clinical treatment of NIHL or NID; (4) studies on the clinical diagnosis of NIHL or NID; (5) studies on animal experiments investigating NIHL or NID; (6) studies on noise in cells and genetics; (7) studies on noise with unclear or incomplete results or unclear description of subjects;or (8) books, conferences and news articles on noise exposure.

\section{Data analysis and extraction}

EndNote software was used to screen and extract the relevant literature. Information regarding the study design, type of industry, noise level and hearing loss and general information about the target population were extracted from each study for systematic review and meta-analysis. A meta-analysis is a research study that synthesises and analyses statistical data from multiple independent studies. ${ }^{29}$ Briefly, after relevant questions were formed, the criteria for collecting and selecting literature data were established based on the research purpose. The collected literature data were then characterised and classified. Finally, comprehensive weighted average statistics (eg, overall weighted ORs were calculated based on the characteristics of the studies, including the subject characteristics (eg, sex, age and exposure duration), type of noise (complex noise vs Gaussian noise) and exposure characteristics (noise exposure vs no noise exposure, coexposure to noise and chemicals vs noise exposure). 


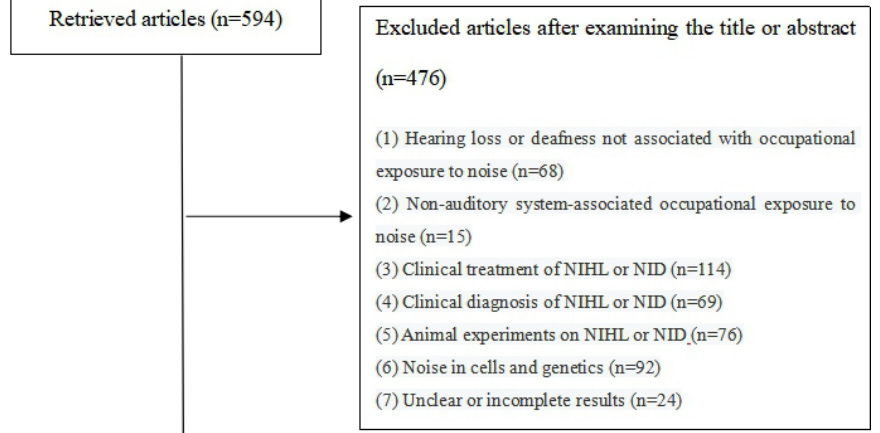

Remaining articles $(\mathrm{n}=118)$

Included articles $(\mathrm{n}=88)$

Figure 1 Flow chart of the selection of articles for metaanalysis. NID, noise-induced deafness; NIHL, noise-induced hearing loss.

A total of 594 articles were retrieved. Among them, 476 were excluded after examining the title or abstract based on the exclusion criteria. Of the 118 articles, 30 were further excluded after reviewing the full text. The remaining 88 articles, which consisted of cross-sectional studies $(79.5 \%)$, cohort studies $(3.4 \%)$ and hot-spot studies $(17.1 \%)$ on exposure to complex noise and

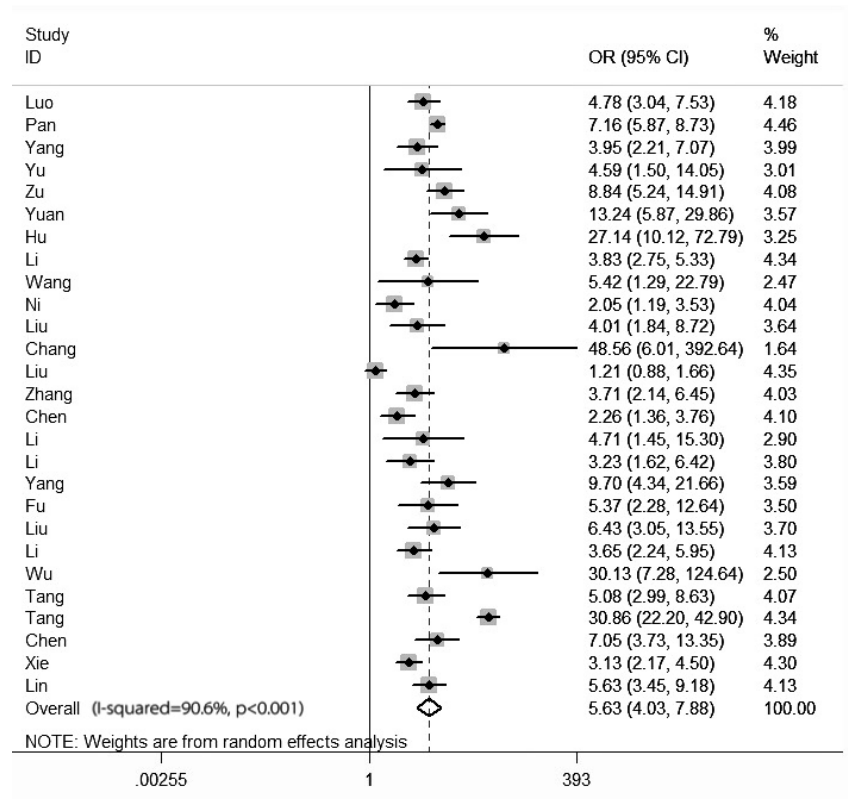

Figure 2 Forest plots of cross-sectional studies. coexposure to noise and chemicals, were included in the systematic review and meta-analysis (figure 1).

Patient and public involvement

No patient involved in the study.

\section{RESULTS}

\section{Cross-sectional studies on NIHL prevalence}

Online supplemental appendix table 1 describes five studies on occupational NIHL in the transportation industry (eg, ship, railway and air transportation), with a total sample size of 5810 workers. For this sector, the maximum level of noise in the workplace was reported to be $97.1 \mathrm{~dB}(\mathrm{~A})$. The prevalence of HFNIHL, SFNIHL and NID among the workers was $11.6 \%, 5.6 \%$ and $5.9 \%$, respectively.

Online supplemental appendix table 2 shows four studies on noise in the mining industry, with a total sample size of 2245 workers. Among the studies, the average maximum level of noise reported in the workplace was $106.2 \mathrm{~dB}(\mathrm{~A})$. The prevalence of HFNIHL, SFNIHL and NID among the workers was $65.1 \%, 7.0 \%$ and $10.3 \%$, respectively.

Online supplemental appendix table 3 shows a total of 34 studies with a total sample size of 34656 workers in the manufacturing industries were analysed. The most common manufacturing industries associated with high noise exposure were typical enterprises, such as automobile manufacturing, air conditioning manufacturing and the textile industry, whose workers were mainly young male adults. The average noise level in these workplaces was $96.2 \pm 5.1 \mathrm{~dB}(\mathrm{~A})$. The prevalence of HFNIHL, SFNIHL and NID was $30.9 \%, 8.5 \%$ and $7.1 \%$, respectively.

\section{Cross-sectional studies with references to NIHL prevalence}

Online supplemental appendix table 4 shows a total of 27 cross-sectional studies with references to occupational NIHL. There were 18319 workers in the exposed groups with average noise levels of $102.2 \pm 7.2 \mathrm{~dB}(\mathrm{~A})$ and 7399 controls with average noise levels of $63.5 \pm 3.8 \mathrm{~dB}(\mathrm{~A})$. The prevalence of HFNIHL among the exposed workers was $28.7 \%$, which was significantly higher than that $(9.9 \%)$ in the controls. The prevalence of SFNIHL was also significantly higher in the exposed groups than in the control groups. The fixed-effects model of the meta-analysis showed that the overall weighted OR for noise exposure as a risk factor for HFNIHL was 5.63 (95\% CI (CI), 4.037.88). Moreover, the forest plot (figure 2) displayed the magnitude and uncertainty of the $95 \%$ CI of OR in each effect size in the dataset. The $95 \%$ CI of OR in each study was $>1$.

\section{Typical cohort studies on NIHL incidence}

Only three cohort studies dynamically investigated hearing loss in 2999 workers from the oil field, electrolytic aluminium and automobile manufacturing industries (table 1). The results showed that the incidence of 
Table 1 Meta-analysis of typical cohort studies on NIHL incidence

\begin{tabular}{|c|c|c|c|c|c|c|c|c|c|}
\hline \multirow[b]{2}{*}{ Author } & \multirow[b]{2}{*}{ Type of factory } & \multicolumn{2}{|c|}{ Population } & \multirow[b]{2}{*}{$\begin{array}{l}\text { Study } \\
\text { duration }\end{array}$} & \multirow[b]{2}{*}{$\begin{array}{l}\text { Years of } \\
\text { follow-up }\end{array}$} & \multirow[b]{2}{*}{$\begin{array}{l}\text { Noise level } \\
\text { (max or } \\
\text { mean)(dB(A)) }\end{array}$} & \multicolumn{3}{|c|}{ NIHL incidence (\%) } \\
\hline & & $\mathbf{N}$ & $\begin{array}{l}\text { Exposure } \\
\text { duration } \\
\text { (years) }\end{array}$ & & & & HFNIHL & SFNIHL & Average \\
\hline Jing $^{59}$ & Oil field & 673 & $1.0-30.0$ & $2006-2010$ & 5 & 106.8 & 30.6 & 3.7 & 17.2 \\
\hline$X u^{60}$ & $\begin{array}{l}\text { Electrolytic } \\
\text { aluminium }\end{array}$ & 1929 & $1.0-30.0$ & 2008-2012 & 5 & $87.1 \pm 2.2$ & 16.6 & 10.9 & 13.8 \\
\hline Total & - & 2999 & $8.8 \pm 8.7$ & 2006-2016 & - & $98.4 \pm 7.2$ & 22.1 & 8.1 & 15.1 \\
\hline
\end{tabular}

$\mathrm{dB}(\mathrm{A})$, A-weighted decibels; HFNIHL, high-frequency noise-induced hearing loss; NIHL, noise-induced hearing loss; SFNIHL, speechfrequency noise-induced hearing loss.

HFNIHL and SFNIHL in these sectors was $22.1 \%$ and $8.1 \%$, respectively. Moreover, cumulative noise exposure (CNE) was shown to aggravate hearing loss, and the length of service was positively correlated with the incidence of hearing loss.

\section{Hot-spot research on noise exposure and NIHL}

$\mathrm{NIHL}$ associated with complex noise

Seven studies were about NIHL associated with complex noise versus Gaussian noise. There were no significant differences in CNE, noise level, age or sex between the Gaussian noise groups and complex noise groups $(\mathrm{p}>0.05)$ (table 2). The kurtosis of complex noise $(33.0 \pm 51.7)$ was significantly higher than that of Gaussian noise (3.3 \pm 0.3$)$. The prevalence of HFNIHL in the complex noise groups was $34.5 \%$, which was significantly higher than that $(25.6 \%)$ in the Gaussian noise groups $\left(\chi^{2}\right.$ test, $\left.\mathrm{p}<0.01\right)$. The fixed-effects model of the meta-analysis showed that the overall weighted OR for complex noise affecting HFNIHL prevalence was 1.95 .

\section{$\mathrm{NIHL}$ associated with coexposure to noise and chemicals}

Table 3 shows eight studies regarding NIHL associated with coexposure to noise and chemicals (eg, dust, benzene, welding fumes, n-hexane, hydrogen, carbon, ethylbenzene) versus exposure to noise alone. There were no significant differences in noise level, age or sex between the noise groups and coexposure groups $(p>0.05)$. Moreover, the prevalence of coexposure to noise and chemicals was $54.2 \%$, which was significantly higher than that of exposure to noise alone $(30.3 \%)\left(\chi^{2}\right.$ test, $\mathrm{p}<0.01)$. The fixed-effects model of the meta-analysis showed that the overall weighted OR for coexposure to noise and chemicals was 2.36.

\section{Summary of the epidemiological characteristics of occupational NIHL}

A total of 71865 workers (males, $82.7 \%$ ) aged $33.5 \pm 8.7$ years, who had an average noise exposure duration of $9.9 \pm 8.4$ years, were included in this study (table 4 ). Their average levels of noise exposure were $98.6 \pm 7.2 \mathrm{~dB}(\mathrm{~A})$, and most of them were from the transportation, mining and manufacturing industries. Combining all the data, we found that the general prevalence of occupational NIHL during the past 26 years in China was $21.3 \%$, of which $30.2 \%, 9.0 \%$ and $5.8 \%$ accounted for the prevalence of HFNIHL, SFNIHL and NID, respectively. The overall weighted ORs for noise, complex noise, coexposure to noise and specific chemicals, male sex, age and exposure duration were $5.63,1.95,2.36,2.26,1.35$ and 1.75 , respectively (table 5).

\section{DISCUSSION}

This study reviewed and analysed literature data on occupational NIHL in China in the past 26 years. The results showed that workers with NIHL was mainly from typical manufacturing industries (eg, textile, automobile manufacturing, metal processing). ${ }^{30} 31$ Our findings are consistent with those in other countries. In the USA, workers at risk of occupational NIHL include those employed in construction, manufacturing, mining, agriculture, utilities, transportation and the military, as well as musicians, ${ }^{5}$ with approximately $82 \%$ of workers with hearing loss coming from the manufacturing industries. ${ }^{32}$ In Asia, sources of noise pollution mainly comprise the manufacturing, transportation, mining and agricultural industries. ${ }^{13} 33$ In this study, we found that the average noise level for Chinese workers from these industries was $98.6 \pm 7.2 \mathrm{~dB}(\mathrm{~A})$, which exceeds the occupational exposure limit of $85 \mathrm{~dB}(\mathrm{~A})$. Noise intensity was positively correlated with the prevalence of hearing loss (overall weighted $\mathrm{OR}=5.63$ ). The general prevalence of NIHL in China was $21.3 \%$, of which $30.2 \%$ is related to highfrequency hearing loss. These findings suggest that the wide distribution of noise in different industries, high levels of noise exposure and long-term exposure to noise in the workplace were the main risk factors for the high prevalence of NIHL in China.

Our findings on the prevalence and characteristics of noise exposure and NIHL in China are similar to those in other countries. For instance, Soltanzadeh et al reported that the occupational noise level in Iran reached 90.29 $\mathrm{dB}(\mathrm{A})$, while the overall hearing threshold was $26.44 \pm 8.09$ $\mathrm{dB} .{ }^{5}$ Kim also reported that $>90 \%$ of the workplace noise 


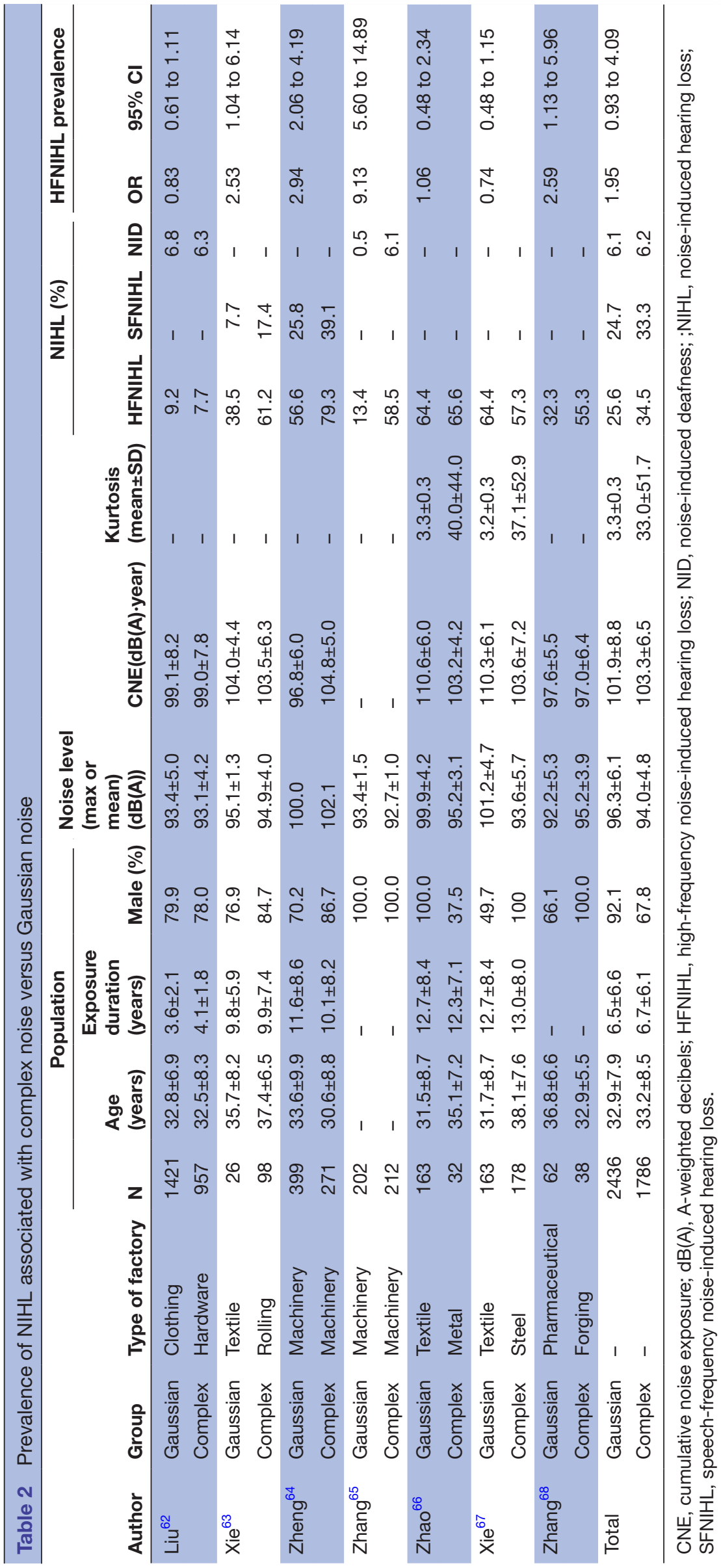




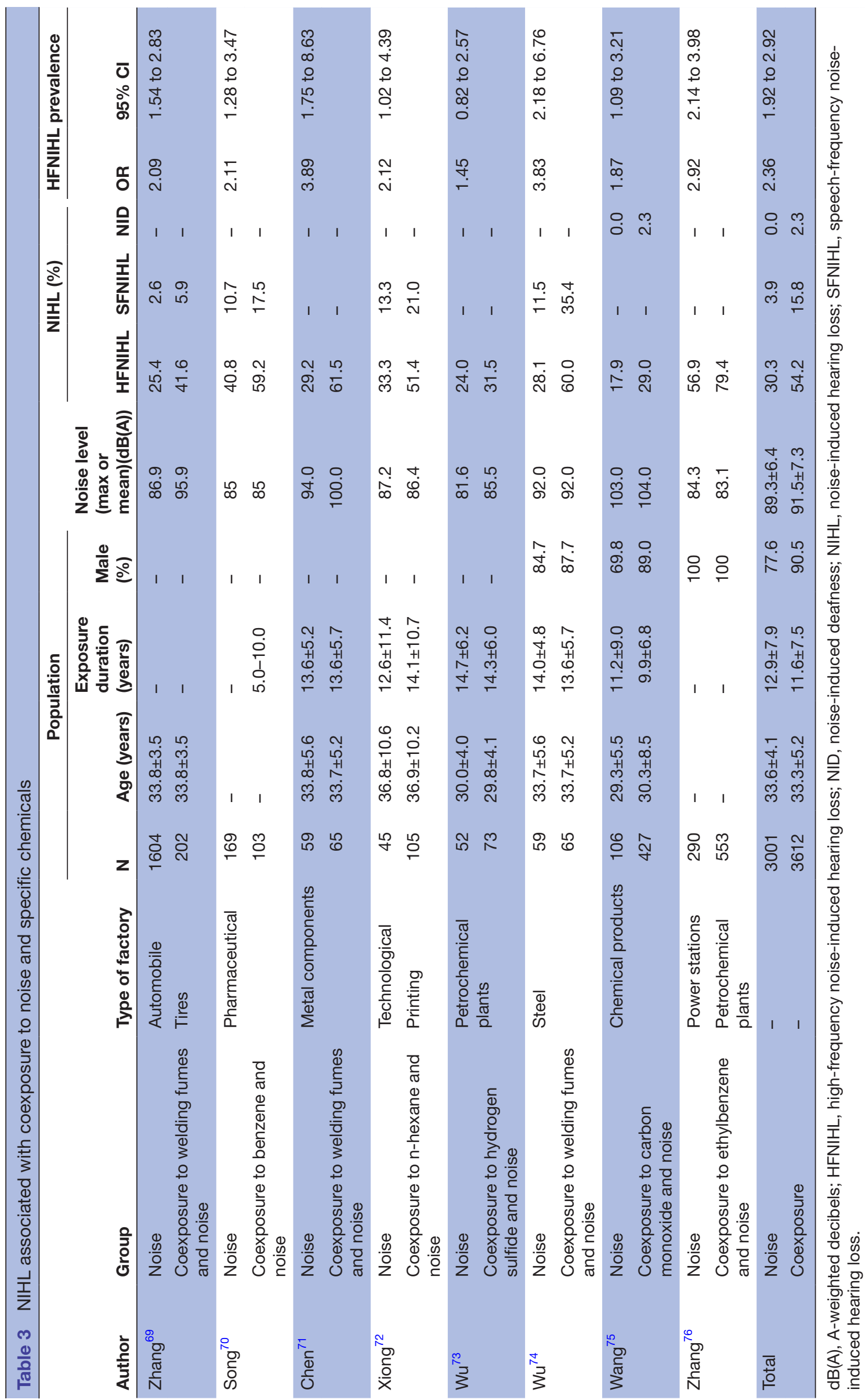




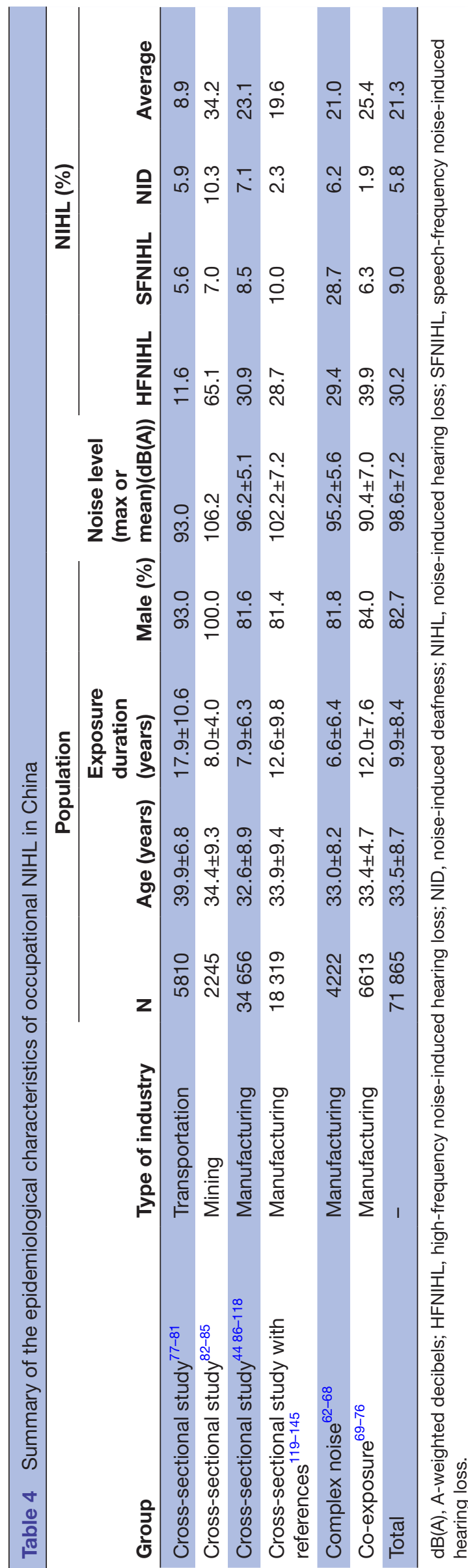

levels in South Korea exceeded the occupational exposure limit, and $92.9 \%$ of suspected occupational diseases were occupational NID. ${ }^{34}$ The Centers for Disease Control and Prevention estimate that about 9 million workers are exposed to daily average sound levels of $\geq 85 \mathrm{~dB}(\mathrm{~A})$ and about 26 million Americans experience NIHL, with a prevalence of $15 \% .{ }^{35}$ Rubak et al also found a doseresponse relationship between NIHL and noise intensity among workers in Denmark, that is, a higher noise level was associated with a higher prevalence of NIHL. ${ }^{37}$

The occurrence of NIHL is usually affected by individual factors such as sex and age. In this study, the average age of the workers was $33.5 \pm 8.7$ years, and the risk of HFNIHL increased with age. Meanwhile, sex was risk factor for HFNIHL, with its prevalence being significantly higher in men than in women. These findings are consistent with those of other studies. Most cases of occupational NID in developed areas of China occurred in young adults, with an average age of 40 years. ${ }^{38}{ }^{39}$ Some studies also showed that the prevalence of NIHL in workers with high noise exposure was significantly higher in men than in women, and the workers with NIHL comprised young and middleaged people. ${ }^{40-42}$ Although the hearing threshold was already adjusted for age in most studies, age might still influence the occurrence of HFNIHL. ${ }^{41} 43$

In this review, the average duration of noise exposure among Chinese workers was $9.9 \pm 8.4$ years, which could be a significant contributing factor to the prevalence of high-frequency hearing loss (overall weighted $\mathrm{OR}=1.75$ ). NIHL can result from the cumulative effects of increased durations and levels of noise exposure. High noise levels can damage the outer hair cells, but with continuous noise exposure, the damage can extend to the inner hair cells, supporting cells, cochlear vascularis and spiral ganglion cells. ${ }^{39}$ Results of previous studies have shown that the general prevalence of NIHL increased with exposure duration, with the disease developing rapidly during the first 10 years of exposure, reaching a peak in 10-15 years, and then entering a plateau after 15 years. ${ }^{44-46}$

This study also showed that exposure to complex noise among workers led to a greater risk of hearing loss than exposure to Gaussian noise did. The kurtosis for the complex noise group was higher than that for the Gaussian noise group, and there were no significant differences in noise energy levels between both groups. The overall weighted OR for complex noise was 1.95 . These findings indicate that the temporal structure of complex noise was a new determinant for NIHL. Moreover, the ORs in the machinery subgroups were 9.13 and 2.94, which were relatively higher than those in other subgroups. The reason might be related to the complexity of the temporal structure of noise generated from mechanical processes, making complex noise from the machinery industry a greater contributor to HFNIHL than complex noise from other industries. ${ }^{15} 47$ Animal experiments have shown that complex noise was more destructive to the hearing of chinchillas than Gaussian noise, and these studies have recommended that the 
Table 5 ORs for key factors influencing HFNIHL prevalence

\begin{tabular}{|c|c|c|c|c|c|}
\hline No & Factor & Group & HFNIHL (\%) & $\begin{array}{l}\text { Overall weighted OR for } \\
\text { HFNIHL }\end{array}$ & $95 \% \mathrm{Cl}$ \\
\hline 1 & Noise & Noise & 28.7 & 5.63 & 4.03 to 7.88 \\
\hline \multirow[t]{2}{*}{2} & Complex noise & Complex noise & 34.5 & 1.95 & 1.06 to 7.84 \\
\hline & & Gaussian noise & 25.6 & & \\
\hline \multirow[t]{2}{*}{4} & Sex & Male & 17.5 & 2.26 & 1.62 to 3.19 \\
\hline & & Female & 7.2 & & \\
\hline \multirow[t]{2}{*}{5} & Age & Age $>33$ years & 29.8 & 1.35 & 1.30 to 1.40 \\
\hline & & Age $\leq 33$ years & 23.9 & & \\
\hline
\end{tabular}

HFNIHL, high-frequency noise-induced hearing loss.;

kurtosis reflecting the temporal structure of complex noise is a good parameter for classifying the effects of complex noise versus Gaussian noise. ${ }^{15} 16$ Several epidemiological studies have also demonstrated that exposure to complex noise could lead to greater hearing loss than exposure to Gaussian noise and that the standard noise limit recommended by ISO-1999 was not within the safe threshold. ${ }^{48} 49$ A typical impulse noise was also reported to cause more hearing damage than continuous noise. ${ }^{50}$ Moreover, cross-sectional studies considered the kurtosis metric combined with noise energy as a good parameter for determining and preventing the hazards to hearing posed by industrial environments with high noise levels. ${ }^{45152}$

In addition to noise, other occupational hazards might affect the hearing of workers. This study showed that combined exposure to noise and specific chemicals (eg, organic solvents, welding fumes, carbon monoxide and hydrogen sulfide) aggravated hearing loss (overall weighted $\mathrm{OR}=2.36$ ). The combined effects might be related to auditory neurotoxicity induced by these chemicals. Animal experiments have demonstrated that solvents such as toluene, styrene, xylene and ethyl benzene could affect the auditory function through their toxic action on the organ of Corti, the auditory pathways and the middle-ear reflex. ${ }^{53}$ Zhang et al reported that styrene might have an effect on the auditory system, and the combined effects of toluene, xylene, and noise could lead to a significant increase in the hearing threshold. ${ }^{54}$ Campo et alfound that the temporal structure of noise was able to modify the ototoxicity of styrene in experimental animals and a moderate level of styrene enhanced the cochlear damage caused by impulse noise. A pilot study showed that workers exposed to non-Gaussian noise and solvents presented a significantly worse hearing threshold than those exposed only to non-Gaussian noise. ${ }^{55}$ A metaanalysis also showed that among 7530 industrial workers, those exposed to both noise and organic solvents had a significantly greater risk of hearing loss than those exposed to noise alone. ${ }^{26}$ Furthermore, as previously mentioned, several epidemiological studies have shown that exposure to various organic solvents was associated with an excessive risk of developing hearing loss, with or without concurrent noise exposure, in humans. ${ }^{56-58}$

This study has several limitations. The number of Chinese studies focusing on SFNIHL and deafness was limited, resulting in an insufficient sample in these categories. There was also a lack of well-designed prospective studies on noise, which made it impossible to determine the incidence of NIHL in China. Only three cohort studies with 2999 subjects were included in this study, and the rest were mainly cross-sectional studies; therefore, the determination of correlation between occupational exposure factors and NIHL was limited.

\section{CONCLUSIONS}

Based on the above findings, the following conclusions could be drawn: (1) In China, a large proportion of the population exposed to occupational noise comprised young male manufacturing workers, and the average duration of exposure to harmful noise levels was $>9.0$ years. The general prevalence of occupational NIHL in China was $21.3 \%$, and among the types of NIHL, HFNIHL had the highest prevalence; (2) The prevalence of HFNIHL increased with higher noise levels and higher duration of exposure and was affected by individual factors such as age and sex; (3) Exposure to complex noise and coexposure to noise and specific chemicals could increase the risk of occupational NIHL and (4) Finally, the high prevalence of occupational NIHL in China was related to the wide distribution of noise in different industries as well as high-level and long-term noise exposure. 
Our findings suggest the need for additional efforts to reduce noise exposure among Chinese workers, which are made possible by carrying out industrial noise monitoring and risk assessment of hearing loss, further strengthening the implementation of hearing protection programmes for workers, and conducting well-designed epidemiological studies on industrial noise, complex noise, and coexposure to noise and chemicals.

Contributors JZ contributed to study design and implementation, and data analysis. ZS contributed to literature review. LZ and HY contributed to data collection and analysis. MZ contributed to study design, quality control and article review.

Funding This work was supported by the Zhejiang Provincial Key Research and Development Project (2015C03039); the Zhejiang Provincial Programme for the Cultivation of High-Level Innovative Health Talents, National Nature Science Foundation of China (81472961); and the Health Commission of Zhejiang Province (2019KY057).

Competing interests None declared.

Patient consent for publication Not required.

Provenance and peer review Not commissioned; externally peer reviewed.

Data availability statement № data are available.

Open access This is an open access article distributed in accordance with the Creative Commons Attribution Non Commercial (CC BY-NC 4.0) license, which permits others to distribute, remix, adapt, build upon this work non-commercially, and license their derivative works on different terms, provided the original work is properly cited, appropriate credit is given, any changes made indicated, and the use is non-commercial. See: http://creativecommons.org/licenses/by-nc/4.0/.

ORCID iD

Jiena Zhou http://orcid.org/0000-0002-6839-737X

\section{REFERENCES}

1 World Health Organization. Prevention of blindness and deafness. Available: http://www.who.int/pbd/deafness/estimates/en/

2 Oishi N, Schacht J. Emerging treatments for noise-induced hearing loss. Expert Opin Emerg Drugs 2011;16:235-45.

3 Beyan AC, Demiral Y, Cimrin AH, et al. Call centers and noiseinduced hearing loss. Noise Health 2016;18:113-6.

4 Konings A, Van Laer L, Van Camp G, Laer LV, Camp GV. Genetic studies on noise-induced hearing loss: a review. Ear Hear 2009;30:151-9.

5 Soltanzadeh A, Ebrahimi H, Fallahi M, et al. Noise induced hearing loss in Iran: (1997-2012): systematic review article. Iran J Public Health 2014;43:1605-15.

6 National Institute for Occupational Safety and Health (NIOSH). Noise and hearing loss prevention, 2013. Available: http://www.cdc. gov/niosh/topics/noise/

7 Meyer JD, Chen Y, McDonald JC, et al. Surveillance for workrelated hearing loss in the UK: OSSA and OPRA 1997-2000. Occup Med 2002;52:75-9.

8 Lie A, Skogstad M, Johnsen TS, et al. The prevalence of notched audiograms in a cross-sectional study of 12,055 railway workers. Ear Hear 2015;36:e86-92.

9 Chen Y, Zhang M, Qiu W, et al. Prevalence and determinants of noise-induced hearing loss among workers in the automotive industry in China: a pilot study. J Occup Health 2019;61:387-97.

10 Chen J, Cai RD, Xiang LJ, et al. Research progress on the related influencing factors of noise-induced hearing impairment. Chin Occup Med 2017;44:235-8.

11 Department of Planning, Development and Information Technology. Statistical bulletin on health development in China in 2018. Available: http://www.nhc.gov.cn/guihuaxxs/s10748/201905/9b8d 52727cf346049de8acce25ffcbd0.shtml [Accessed 5 Jun 2019].

12 YH L, Jiao J, SF Y. Research status of influencing factors of noiseinduced hearing loss. Chin J Occup Dis 2014;32:469-73.

13 Fuente A, Hickson L. Noise-induced hearing loss in Asia. Int J Audiol 2011;50:S3-10.

14 Nandi SS, Dhatrak SV. Occupational noise-induced hearing loss in India. Indian J Occup Environ Med 2008;12:53-6.
15 Hamernik RP, Qiu W. Energy-independent factors influencing noiseinduced hearing loss in the chinchilla model. J Acoust Soc Am 2001;110:3163-8.

16 Suter $\mathrm{AH}$. Occupational hearing loss from non-Gaussian noise. Semin Hear 2017;38:225-62.

17 International Organization for Standardization. ISO 1999:1990 acoustics-determination of occupational noise exposure and estimation of noise-induced hearing impairment. 2 edn. Geneva, Switzerland: International Organization for Standardization, 1990.

18 International Organization for Standardization. ISO 1999:2013 acoustics-estimation of noise-induced hearing loss. 3 edn. Geneva, Switzerland: International Organization for Standardization, 2013.

19 Ministry of Health. People's republic of China national occupational health GBZ/T 189-2007. China: MOH, 2007.

20 State Administration of Work Safety of the People's Republic of China. People's republic of China safety industry standard: guidelines for occupational disease inductive risk management of noise AQ/T 4276, 2016.

21 Health and Safety Executive. The control of noise at work regulations. UK: The Stationery Office Limited, 2005.

22 Goley GS, Song WJ, Kim JH. Kurtosis corrected sound pressure level as a noise metric for risk assessment of occupational noises. $J$ Acoust Soc Am 2011:129:1475-81.

23 Qiu W, Zhang MB, WC X, et al. Application of kurtosis in assessing hearing loss caused by complex noise. J Chin Ear Science 2016:701-7.

24 Turcot A, Girard SA, Courteau M, et al. Noise-induced hearing loss and combined noise and vibration exposure. Occup Med 2015;65:238-44.

25 Yang $\mathrm{H}-\mathrm{Y}$, Shie R-H, Chen P-C. Hearing loss in workers exposed to epoxy adhesives and noise: a cross-sectional study. BMJ Open 2016;6:e010533.

26 Hormozi M, Ansari-Moghaddam A, Mirzaei R, et al. The risk of hearing loss associated with occupational exposure to organic solvents mixture with and without concurrent noise exposure: a systematic review and meta-analysis. Int $\mathrm{J}$ Occup Med Environ Health 2017;30:521-35.

27 Estill CF, Rice CH, Morata T, et al. Noise and neurotoxic chemical exposure relationship to workplace traumatic injuries: a review. $J$ Safety Res 2017;60:35-42.

28 Ministry of Health. Diagnosis of occupational noise deafness GBZ 49-2014. China: MOH, 2014.

29 Buchwald $\mathrm{H}$, Avidor $\mathrm{Y}$, Braunwald E, et al. Bariatric surgery: a systematic review and meta-analysis. JAMA 2004;292:1724-37.

30 Yu SF, Chen GS, Jiao J, et al. [A cohort study on occupational noise induced hearing loss in workers at an iron and steel plant]. Zhonghua Yu Fang Yi Xue Za Zhi 2017;51:13-19.

31 Yongbing S, Hal Martin W, Martin WH. Noise induced hearing loss in China: a potentially costly public health Lssue. J Otol 2013;8:51-6.

32 National Institute for Occupational Safety and Health (NIOSH). Noise and hearing loss prevention: facts and statistics. Available: http://www.cdc.gov/niosh/topics/noise/ stats.html

33 Stucken EZ, Hong RS. Noise-induced hearing loss: an occupational medicine perspective. Curr Opin Otolaryngol Head Neck Surg 2014;22:388-93.

$34 \mathrm{Kim} \mathrm{KS}$. Occupational hearing loss in Korea. J Korean Med Sci 2010;25:S62-9.

35 Masterson EA, Deddens JA, Themann CL, et al. Trends in worker hearing loss by industry sector, 1981-2010. Am J Ind Med 2015;58:392-401.

36 Shargorodsky J, Curhan SG, Curhan GC, et al. Change in prevalence of hearing loss in US adolescents. JAMA 2010;304:772-8.

37 Rubak T, Kock SA, Koefoed-Nielsen B, et al. The risk of noiseinduced hearing loss in the Danish workforce. Noise Health 2006;8:80-7.

38 Chen WX, Huang YL, Xie YQ, et al. Investigation and analysis of noise hazards in Foshan city from 2007 to 2016. Zhonghua Lao Dong Wei Sheng Zhi Ye Bing Za Zhi 2019:132-3.

39 Zhu W, Ding B, Sheng H, et al. [Occupational noise-induced deafuess diaqnosis analysis in Jiangsu from 2006 to 2009]. Zhonghua Lao Dong Wei Sheng Zhi Ye Bing Za Zhi 2015;33:671-3.

40 Seixas NS, Neitzel R, Stover B, et al. 10-year prospective study of noise exposure and hearing damage among construction workers. Occup Environ Med 2012;69:643-50.

41 Lie A, Skogstad M, Johnsen TS, et al. A cross-sectional study of hearing thresholds among 4627 Norwegian train and track maintenance workers. BMJ Open 2014;4:e005529. 
42 Lie A, Skogstad M, Johannessen HA, et al. Occupational noise exposure and hearing: a systematic review. Int Arch Occup Environ Health 2016;89:351-72.

43 Samant Y, Parker D, Wergeland E, et al. The Norwegian labour inspectorate's registry for work-related diseases: data from 2006 Int J Occup Environ Health 2008;14:272-9.

$44 \mathrm{YQ}$ L, Shao RQ. Research on the hazard of production noise in a steel pipe manufacturing enterprise. Zhejiang J Prev Med 2015;27:298-9.

45 Bauer P, Körpert K, Neuberger M, et al. Risk factors for hearing loss at different frequencies in a population of 47,388 noise-exposed workers. J Acoust Soc Am 1991;90:3086-98.

46 Chen TJ, Chiang HC, Chen SS. Effects of aircraft noise on hearing and auditory pathway function of airport employees. J Occup Med 1992;34:613-9.

47 Qui W, Zhang M, Xu W, et al. The application of the kurtosis metric in evaluating hearing trauma from complex noise exposures. Chin $J$ Otology 2016

48 Seixas N, Neitzel R, Sheppard L, et al. Alternative metrics for noise exposure among construction workers. Ann Occup Hyg 2005;49:493-502.

49 Seixas NS, Neitzel R, Stover B, et al. 10-year prospective study of noise exposure and hearing damage among construction workers. Occup Environ Med 2012;69:643-50.

50 Clifford RE, Rogers RA. Impulse noise: theoretical solutions to the quandary of cochlear protection. Ann Otol Rhinol Laryngol 2009;118:417-27.

51 Davis RI, Qiu W, Heyer NJ, et al. The use of the kurtosis metric in the evaluation of occupational hearing loss in workers in China: implications for hearing risk assessment. Noise Health 2012:14:330-42.

52 Davis RI, Qiu W, Hamernik RP. Role of the kurtosis statistic in evaluating complex noise exposures for the protection of hearing. Ear Hear 2009;30:628-34.

53 Wathier L, Venet T, Thomas A, et al. Membrane fluidity does not explain how solvents act on the middle-ear reflex. Neurotoxicology 2016;57:13-21.

54 Zhang M, Xu P, Gu Q. [Research progress on ototoxicity and hearing loss effects of organic solvents]. Zhonghua Lao Dong Wei Sheng Zhi Ye Bing Za Zhi 2016;34:873-7.

55 Fuente A, Qiu W, Zhang M, et al. Use of the kurtosis statistic in an evaluation of the effects of noise and solvent exposures on the hearing thresholds of workers: an exploratory study. J Acoust Soc Am 2018;143:1704-10.

56 Campo P, Morata TC, Hong O. Chemical exposure and hearing loss. Dis Mon 2013:59:119-38.

57 Unlu I, Kesici GG, Basturk A, et al. A comparison of the effects of solvent and noise exposure on hearing, together and separately. Noise Health 2014;16:410-5.

$58 \mathrm{Kim}$ J, Park H, Ha E, et al. Combined effects of noise and mixed solvents exposure on the hearing function among workers in the aviation industry. Ind Health 2005;43:567-73.

59 Jing QS, Zang J, Wang CL. Hearing examination results of drilling workers in an oil field from 2006 to 2010. J Occup Health 2012;28:19-21.

60 Xu T, Ding WQ, Song Y, et al. Investigation on the hearing impairment of noise-exposed workers in an enterprise. Sichuan Med Science 2014;35:509-12.

$61 \mathrm{XL} \mathrm{H}, \mathrm{FH}$ L, Xia AL, et al. Investigation on hearing loss of noiseexposed workers in an automobile manufacturing company. Chin $J$ Indus Med 2017;30:40-2.

62 Liu XX, Guo ZP, Huang GX, et al. A comparative study on hearing damage caused by Gaussian and non-Gaussian noise in workers. Occup Health Emerg Rescue 2010;28:87-90.

63 Xie HW, Zhang MB, Quan CJ. Relationship between cumulative exposure to non-Gaussian noise and hearing loss. Environ Occup Med 2014;26:340-8

64 Zheng JR, Wan WX, Zhao YM. Study on the effect of impulse noise in mechanical industry on hearing of workers. Chin J Indus Med 1997;10:19-20.

65 Zhang J. Effects of pulse and Gaussian-state noise on hearing and cardiovascular system of workers. J Occup Med 2010;26.

66 Zhao Y-ming, Qiu W, Zeng L, et al. Application of the kurtosis statistic to the evaluation of the risk of hearing loss in workers exposed to high-level complex noise. Ear Hear 2010;31:527-32.

67 Xie H-wei, Qiu W, Heyer NJ, et al. The use of the kurtosis-adjusted cumulative noise exposure metric in evaluating the hearing loss risk for complex noise. Ear Hear 2016;37:312-23.

68 Zhang GY, Tang ZF, Yao YP. A comparative study of high-frequency hearing impairment caused by noise from punching machine and steady state noise in workers. Chin J Occup Med 2012;30:356-8.
69 Zhang JX, SH X, XG Y, et al. Analysis of hearing loss and related factors in noise-exposed workers in tire manufacturing industry. Chin Occup Med 2018;45:143-6.

70 Song J, Ma J. Effects of smoking on noise-induced hearing loss. Modern Prev Med 2008;35:4572-3.

71 Chen XX, JY L, SS S. Investigation on hearing impairment of workers under combined effects of welding smoke and noise. Chin J Occup Med 2009;36:87-8.

72 Xiong YJ. Effects of $n$-hexane combined with noise on hearing loss Modern Prev Med 2014;41:2724-6.

73 QF W, Li C, Liang XY, et al. Effects of noise combined with high temperature and hydrogen sulfide on hearing impairment. Occup Health Emerg Rescue 2012;30:16-18.

74 Wu L, Zhu ZC, LF Y, et al. Effects of welding dust and noise on hearing loss in workers. Chin Public Health 2009;25:75-6.

75 Wang GM, Chen XM, Wang XL. Effects of combined noise and carbon monoxide on hearing. J Med Animal Control 2006;22:697-8.

76 Zhang M, Wang Y, Wang Q, et al. Ethylbenzene-induced hearing loss, neurobehavioral function, and neurotransmitter alterations in petrochemical workers. J Occup Environ Med 2013;55:1001-6.

77 MS H, Yang J, Jin HB, et al. A sampling survey on the hearing status of civil aviation air traffic controllers. Chin J Otolaryngology Head Neck Surg 2018;25:131-5.

78 Rong X, LX W, Hu D, et al. Analysis on hearing loss of 2045 locomotive drivers. Environ Occup Med 2016;33:319-24.

79 SS G, Zheng GL, Cai WR, et al. An analysis on the hearing loss of seafarers caused by noisy environment. Chin J Marine Med Hyperbaric Med 2014;21:105-8.

80 TG X, Zhao ZR. Survey of warship noise and its effect on hearing loss of naval officers. J Naval Med College China 1997:213-5.

81 Peng Y, Fan C, Hu L, et al. Tunnel driving occupational environment and hearing loss in train drivers in China. Occup Environ Med 2019;76:97-104.

82 Zhang HC, Yue PP. Hearing loss in blasting, tunneling and mining workers in a mining enterprise. J Occup Health 2013;29:3076-9.

83 Yuan JW, Cao SQ, Feng Q. Effects of oil field noise on workers' hearing and electrocardiogram. Chin J Indus Med 2001;14:116-7.

84 Zhao JF, QX X, HM L. Analysis of hearing test results of noiseexposed workers in a coal mine of a city. Occup Health Emerg Rescue 2016;34:394-5.

85 Zhang G, Tang Z, Yao Y, et al. Investigation of noise hazards and hearing status of workers in outdoor quarries. Zhonghua Lao Dong Wei Sheng Zhi Ye Bing Za Zhi 2014;32:597-9.

86 Chen M, Lin MZ, Chen YQ, et al. Analysis on data of physical examination in workers exposed to noise in a machinery factory of Huli district in Xiamen City. J Occup Health 2013;29:3282-4.

87 Gao T, XN W. Investigation on noise exposure and hearing loss of steel rolling workers in a steel company. Chin Med Clinic 2010;10:1017-9.

88 Gao WW, Xia GH, Ji K, et al. Epidemiological investigation on occupational noise and hearing loss in Beilun district, Ningbo city. Zhejiang Med Science 2011;33:1727-8.

89 Gao Y, Huang QF, Guo JJ, et al. Hearing loss and risk factors of workers exposed to noise in a toy factory. J Occup Health 2017;33:1172-4

90 Jiao Y, Fan SH. Analysis on pure tone audiometry results of 520 exposures of workers exposed to noise. Chin Pract Med 2014:268-9.

91 CF L, He Y, DL L, et al. Survey report on noise classification and health status of workers in Xifei company. J Aerospace Med 2002;13:47-8

92 Lin L, Liu Q, Wang JY, et al. Epidemiological study on occupational noise and hearing loss in Longgang district, Shenzhen. J Occup Health 2008;24:511-3.

93 Liu F, Song WM. Analysis of hearing exposure results of noiseexposed workers in an oxygen plant. Chin Dept Otolaryngology Head Neck Surg 2010;17:653-5.

94 SQ L, Shao LH, Wang JX, et al. Dose-response relationship between noise exposure and the prevalence of hearing loss in male aircraft maintenance workers. Chin J Indus Med 2003:277-9.

95 Wang JY, Xiao QH, Xia Y, et al. Discussion on the relationship between cumulative noise exposure and noise-induced hearing loss. Occup Health Emerg Rescue 2009;27:131-3.

96 Wang RL, Zhao YM. Investigation on the working age and hearing loss of workers in a textile factory. Capital Public Health 2015:9:207-9.

97 Yan XK, Dai P, Xue XJ, et al. Investigation on hearing loss of tank soldiers. People's Army Doctor 2008;51:202-4.

98 Yan YL, Tan HY, XX H. Investigation and prediction of hearing loss in 528 subjects exposed to non-Gaussian noise. Chin J Occup Med 1993:73-4. 
99 Guo Y, Han SQ, YH X. Investigation on the relationship between hearing loss, length of service and cumulative noise exposure of workers exposed to noise in a textile factory. Contemporary Chin Med 2012;19:150-4.

100 Nie W, WJ H. Survey on noise hazard of shipbuilding enterprises. Chin J Indus Med 2016:167-70.

101 Wang LY, Dong HL, Zhang W. Investigation on noise hazard in cotton textile industry. Chin J Indus Med 2003:364-5.

102 Zhang XH, Zhu YM, Xia YY. Dose-response relationship between hearing loss and noise exposure in Gaussian noise-exposed workers. Chin J Indus Med 2001;14:72-4.

$103 \mathrm{CH}$ N, Chen ZY, Zhou Y, et al. Associations of blood pressure and arterial compliance with occupational noise exposure in female workers of textile Mill. Chin Med J 2007;120:1309-13.

104 Xie HW, Tang SC, Zhou LF, et al. Relationship between cumulative exposure to non-Gaussian noise and hearing loss. Environ Occup Med 2015;32:56-60.

105 Chen Y, Zhang M, Qu W, et al. Prevalence and determinants of noise-induced hearing loss among workers in the automotive industry in China: a pilot study. J Occup Health 2019;18:387-97.

106 Ning K, Liu C, Li D, et al. Relationship between hearing loss and length of service. $J$ Occup Health 2011;27:1245-7.

107 SC X. Investigation on the effect of pulse noise on hearing injury of workers in forging industry. Shanghai Prev Med 1999;11:553-4.

108 Liu XX, Guo ZP, He J, et al. Dose-response relationship of individual noise protection in occupational exposure population. Chin J Occup Med 2008;35:477-9.

109 Peng LH, Zheng JR, ZG X. Dose-response relationship between cumulative noise exposure and hearing impairment. Public Health Prev Med 2005;16:58-9.

110 Huang WX, GJ W. Investigation on the influence of noise in sawmil workshop of an electronics factory on the five senses of workers. $J$ Occup Med 2004;20:1-2.

111 Chen L, Guo QH. Analysis of high-frequency noise-induced hearing loss of workers in a tire factory. Occup Health Emerg Rescue 2018;36:305-7.

112 Bao EB, YW S, Xue CH, et al. Analysis of influencing factors of hearing loss in noise-exposed workers in an automobile manufacturing enterprise. Occup Health Emerg Rescue 2019;37:122-5

113 You XD, SQ H, Zhang YJ. Epidemiological investigation of noiseinduced deafness among textile workers in Nantong city. Traffic Med 2013;27:38-40.

114 Chen LJ. Relationship between noise exposure and high frequency hearing loss in bottled beverage. Zhonghua Lao Dong Wei Sheng Zhi Ye Bing Za Zhi 2017;35:286-8.

115 Zhang HY, Hua RY, Gao N, et al. Noise hazard and health status of workers in metal processing enterprises in Qinhuangdao city. $J$ Occup Med 2018;34:3155-7.

116 Zhou P, CH L, Yin SW, et al. Effect of noise on welders' hearing. Occup Health Emerg Rescue 2015;33:343-5.

117 Wang LC, Wei YZ, Shan YL, et al. Effects of unsteady noise on hearing of steel rolling workers. Chin J Metall Indus Med 2007;24:612-3.

118 Qian HY, QJ G, Xie S, et al. Noise hazard of welding workers in Zhenjiang city and its influencing factors. J Occup Med 2015;31:2914-7.

119 Luo Y, Zhou LF, Chen J, et al. A survey on the hearing condition of workers working in noise environment in a petrochemical plant. $J$ Audiol Speech Dis 2013;21:532-4.

120 Pan LN, XH W, Feng XL. A survey on the effect of ship noise on crew's hearing. Chin J Occup Med 2009:351-3.

121 Yang F, Liu Z, Zhou Y. Investigation on the influence of ship noise on crew's hearing. Chin J Occup Med 2015:1537-40.
122 RM Y, Zhao HM, Li X, et al. Investigation on noise pollution in military canteen and its effect on the hearing of cooking personnel. North China National Defense Med 2010;22:578-80.

$123 \mathrm{AH} Z$, Cui C, Wang $\mathrm{X}$, et al. Investigation on the effect of industrial impulse noise on the hearing of stamping workers. Int $J$ Med Health 2012;18:429-33.

124 Yuan JG, FM J, Hao J, et al. Investigation on the influence of production noise in forging workshop on male workers' hearing. Zhonghua Lao Dong Wei Sheng Zhi Ye Bing Za Zhi 2005;31:413-4

$125 \mathrm{JH} \mathrm{H}, \mathrm{He} \mathrm{J}$, Lin B, et al. Investigation and analysis of hearing loss in steel pipe factory workers exposed to noise. Chin J Metall Indus Med 2005;22:614-5.

$126 \mathrm{JM} \mathrm{L}, \mathrm{He} \mathrm{J}$, Huang YM, et al. Analysis of hearing level of workers exposed to mechanical noise. Chin J Indus Med 2018;31:49-51.

127 Wang CY, Wang F, BZ W, et al. Epidemiological investigation on hearing loss in home-made GEM processors. Chin J Indus Med 2013:201-3

$128 \mathrm{Ni}$ L, Yao Y, JC L, et al. Analysis of hearing loss in workers exposed to noise in a boiler plant. Chin J Indus Med 2011:16-19.

129 Liu SM, Yao Y, QF W, et al. Investigation on hearing loss of workers exposed to noise from a tobacco company. Chin $\mathrm{J}$ Indus Med 2010:215-7.

130 Chang SJ, Chang CK. Prevalence and risk factors of noise-induced hearing loss among liquefied petroleum gas (LPG) cylinder infusion workers in Taiwan. Ind Health 2009;47:603-10.

131 Liu J, Xu M, Ding L, et al. Prevalence of hypertension and noiseinduced hearing loss in Chinese coal miners. J Thorac Dis 2016;8:422-9.

132 Zhang QN, Chen ZF, Zhong MY, et al. Characteristics of hearing loss in noise-exposed workers in electronic technology enterprises. Int J Med Health 2012;18:424-9.

133 Chen XH, Qiu Y, Li Q, et al. Effects of occupational noise exposure on hearing of workers in a thermal power plant in Guangxi. $J$ Occup Health 2014;30:758-60.

134 BW L, FD L, Zhang YG, et al. Investigation of noise induced hearing impairment in boiler workers. Chin J Occup Health 2003;21:374-5.

135 Li L, Huang JM, HX J, et al. Correlation between cumulative noise exposure and hearing impairment. Prev Med Lit Inf 2000;6:105-6.

136 Yang CM, Qiu Y. An investigation and analysis of the effect of impulse noise on hearing and hearing of working workers. Chin $J$ Occup Med 1999;26:51-2.

137 GY F, Zou ZF, BL L, et al. Effects of steady state noise on hearing in a chemical plant. Chin J of Hyg Eng 2007;6:20-2.

138 Liu LF, Wen L. Effects of production noise on workers' health in a machining enterprise. J Occup Health 2013;29:2133-5.

$139 \mathrm{Li} \mathrm{M}, \mathrm{JH}$ L, Cao DY, et al. Analysis of high-frequency hearing loss of workers in noise operation of an artificial GEM factory. Occup Health Emer Rescue 2006;24:115-6.

140 JY W, XY X, Jiang BY. Effects of noise operation on health of female workers in a shoe factory. J Prev Med 2009;15:67-9.

141 Tang JF, XH T, Wu J. Investigation on hearing loss of 726 workers in Suining city. J Occup Health Injury 2018;33:7-9.

142 Tang MZ, Hua MY. Analysis of occupational health examination results of workers exposed to noise in Wuxi new district. Zhejiang Prev Med 2015;27:82-3.

143 Chen YP, Yang JR. Effects of noise on health of female workers. $J$ Occup Health 2003;19:3-5.

144 Xie S, QJ G, YP L, et al. Health status of workers exposed to noise in a paper-making enterprise of Zhenjiang city. J Occup Health 2013;29:310-31.

145 Lin L, Chen HL, Liu LY, et al. Effects of occupational noise on workers' hearing. Modern Prev Med 2005;32:1234-5. 